\title{
Melt Flow Index of Recycle ABS for Fused Deposition Modeling (FDM) Filament
}

\author{
N. Sa'ude ${ }^{1, a}$, K.Kamarudin ${ }^{2, b}$, M. Ibrahim ${ }^{3, c}$ and M. H. I. Ibrahim. ${ }^{4, d}$ \\ ${ }^{1,2,3}$ Department of Manufacturing and Industrial Engineering, Faculty of Mechanical and \\ Manufacturing Engineering, Universiti Tun Hussein Onn Malaysia(UTHM) \\ 86400 Parit Raja, Batu Pahat, Johor, Malaysia. \\ ${ }^{4}$ Department of Engineering Mechanics, Faculty of Mechanical and Manufacturing Engineering, \\ Universiti Tun Hussein Onn Malaysia(UTHM), 86400 Parit Raja, Batu Pahat, Johor, Malaysia \\ anasuha@uthm.edu.my, ${ }_{d}^{b}$ khairu@uthm.edu.my, ${ }^{c}$ mustaffa@uthm.edu.my, \\ dmdhalim@uthm.edu.my
}

Keywords: FDM, ABS, ABS Recycle, Melt Flow Index

\begin{abstract}
This paper presents the melt flow index (MFI) of acrylonitrile butadiene styrene (ABS) and recycle ABS filament wire for Fused Deposition Modeling(FDM) machine. In this study, the effect of MFI on recycle ABS material was investigated experimentally based on the melting temperature, density, screw speed and material properties. The MFI result on ABS recycle in wire filament was investigated using Melt Indexer Machine(MIM). Based on the result obtained, it was found that, ABS recycle was increase the density and MFI results. It can be observed that, the higher temperature was melt the recycle ABS material through the MIM and extruder machine.
\end{abstract}

\section{Introduction}

ABS material has become a widely used in rapid prototyping technology, especially in fused deposition modeling(FDM) and it was developed by Stratasys Inc., This technology offering a widerange application in prototype development by layered deposition of polymer plastic on the platform in three dimensional object. The process involves a layer by a layer deposition of extruded material through the nozzle using feedstock filaments from a spool. The 3D printing machine was available in the online market with variety's plastic material in filament form with $1.7 \mathrm{~mm} \sim 2.0 \mathrm{~mm}$ in wire diameter. The available 3DP machine brand in the market was Stratasys, Object, Makerbot, Vagler, UP Plus, Prusa I3, EASY3DMAKER, DIY. Normally, the FDM machine involved with either acrylonitrile butadiene styrene (ABS) plastic material $[1,2,3,4,5,6,7,8]$ and Nylon $[9,10]$. Currently, metal filled in the polymer matrix has become an alternative material used in FDM machine. Some researcher used a mix material of ABS-Iron [2,3,9,10,11] and ABS-copper $[12,13]$. Masood et al. and Nikzad et al. mentioned that the critical properties' requirements for high-quality composite are depending on the desired viscosity, strength and modulus. Nevertheless, there are limited data/research dealing with layered deposition of recycle polymer material (LDRP) focuses on melt flow rate. The intention of this study is to investigate the MFI and density of a recycle ABS material from Toys product by MIM at Universiti Tun Hussein Onn Malaysia (UTHM). The research focuses on melt flow rate of a recycle ABS material flow through the $1.5 \mathrm{~mm}$ dies in diameter for the fabrication of filament wire by single screw extruder machine. The proper formulation, mixing and compounding procedure shall be followed for obtaining the homogeneous pallet. The main outcome of this study is to produce a strong, flexible and smooth filament wire of constant diameter with a high melt flow rate by MIM machine. 


\section{Experimental Methods}

\section{Materials}

In the experimental, four(4) types of ABS material was ABS filament, expired ABS filament, ABS pallet and ABS from toys part. ABS filament material was obtained from Advance Material and Manufacturing Centre(AMMC) in Universiti Tun Hussein Onn Malaysia(UTHM). The other ABS pallet is supplied by local company and ABS toys(LEGO brand) was buy from supermarket in Malaysia. ABS materials are an environmental friendly material because they are completely recyclable and a density was $1.03 \mathrm{~g} / \mathrm{cm}^{3}$ with melting temperature $266{ }^{\circ} \mathrm{C}$. Figure 1 and Figure 2 shows the ABS filament material. Figure 3 and Figure 4 shows the ABS pallet form and ABS toys used in the experimental. The amount of each ABS componding is based on the weight in gram $(\mathrm{g})$. ABS material consists of two(2) type which are from filament form and pallet. Firstly, ABS filament materials were chopped into $1 \mathrm{~mm}-5 \mathrm{~mm}$ pallet size. Secondly, ABS toys was crushed by machine into pallet form with a length of $5 \mathrm{~mm}-10 \mathrm{~mm}$ approximately in size and it has been sieved by sieve machine for eliminate the other material and to control the homogenety material. Figure 5 show the crusher machine used in the material preparation in pallet form. Then, ABS from filament and pallet was extruded in the single screw extruder machine (type Y100) in filament form of 1.75 $\mathrm{mm} \sim 1.78 \mathrm{~mm}$ in diameter approximately. The extruder machine consists of 4 zones temperature, where the temperature was a feeding, barrel 1, barrel 2 and nozzle. The extrusion temperature setting was $140{ }^{\circ} \mathrm{C}-240{ }^{\circ} \mathrm{C}$ and screw speed of $4 \mathrm{hz}$ in filament wire fabrication. The selection temperature setting in four(4) temperature zones and screw speed should be synconice in order to produce a constant filament diameter and smoothest material flow through the barrel and nozzle area. Lower temperature setting will lead a brittle material flow and the sticking was occur in the nozzle area. Then a high temperature setting, ABS material become slurry and it difficult to produce a filament wire in constant diameter. Selection of temperature and the screw speed was started from low to high value in order to prevent the kinds of problem. Table 1 show the charecteristic of ABS materials from filament, pallet and toys.

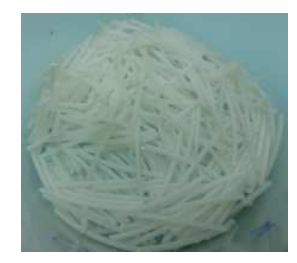

Fig. 1 ABS filament

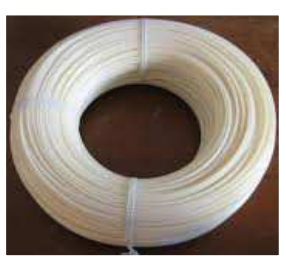

Fig. 2 Expired ABS filamen

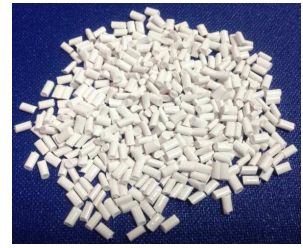

Fig. 3 ABS Pallet

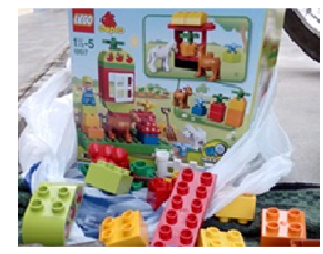

Fig. 4 ABS Toys

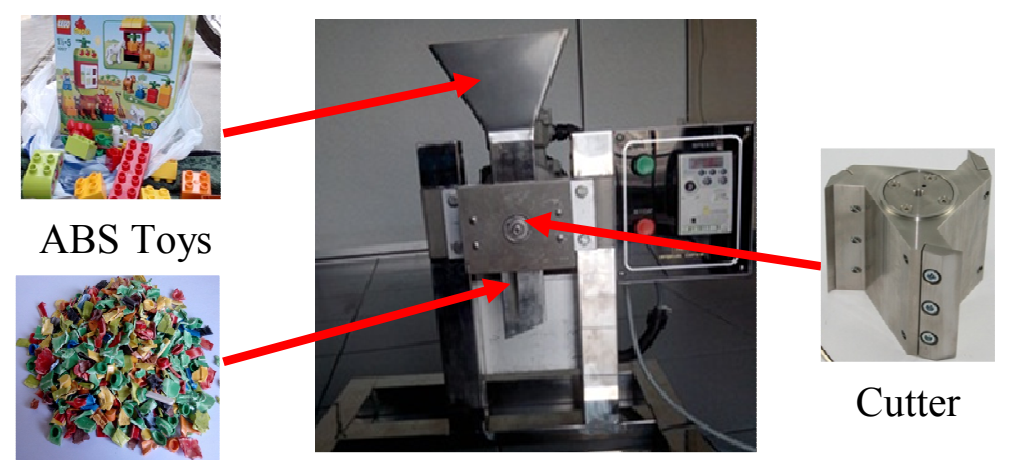

Palletise

Fig. 5 Crusher Machine 


\section{Methods}

In this study, the experiment was done by melt indexer machine(MIM) which is a common equipment used for the melt flow index (MFI) or melt flow rate (MFR). Four(4) types of ABS materials was used in MFR. The selection melting temperature was $180{ }^{\circ} \mathrm{C}$ and standard load is $5 \mathrm{~kg}$. Firstly, pre heated the MIM about 30 minutes for maintain the temperature and standardize preheating time. Then insert $5 \mathrm{~g}-8 \mathrm{~g}$ compounding of $\mathrm{ABS}$ material from pallet and filament in heated barrel for pre heated process in 5 minutes at $180{ }^{\circ} \mathrm{C}$ approximately. Piston load of $5 \mathrm{~kg}$ was placed on the piston rod, and the reading was $25.4 \mathrm{~mm}$ in length was made by stop watch. A wire filament form is produced according to gravity flow in vertical direction. Figure 6 shows the melt indexer machine(MIM) used in the experiment. The highest melt flow rate from four types an ABS material was used in the filament fabrication by single screw extruder machine in constant filament diameter.

Table 1 Characteristic of compounding ABS materials

\begin{tabular}{ccc}
\hline Components & Melt Temperature $\left({ }^{\circ} \mathrm{C}\right)$ & Density $\left(\mathrm{g} / \mathrm{cm}^{3}\right)$ \\
\hline ABS Filament & 266 & 0.971 \\
Expired ABS Filament & 266 & 0.980 \\
ABS Toys & 270 & 0.991 \\
ABS Pallet & 270 & 0.983 \\
\hline
\end{tabular}
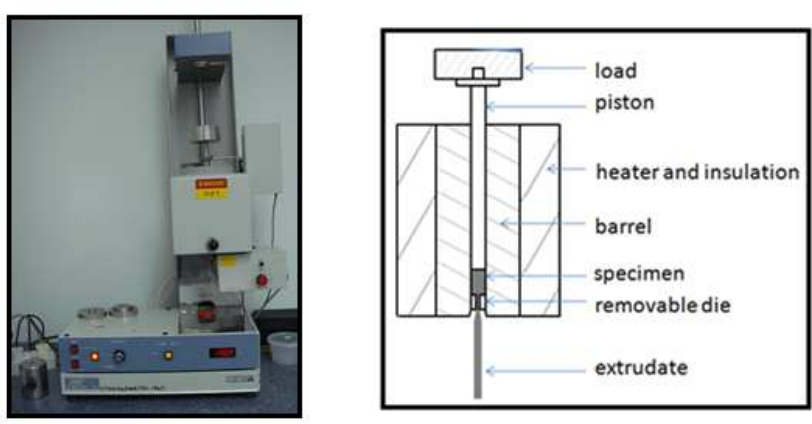

Table 2 MFI Material

\begin{tabular}{ccc}
\hline Material & Density & MFI \\
ABS Filament & 0.971 & 1.567 \\
Expired ABS & 0.980 & 3.500 \\
Filament & & \\
ABS Toys & 0.991 & 4.440 \\
ABS Pallet & 0.983 & 2.210 \\
\hline
\end{tabular}

Figure 6 Melt Indexer Machine(MIM)
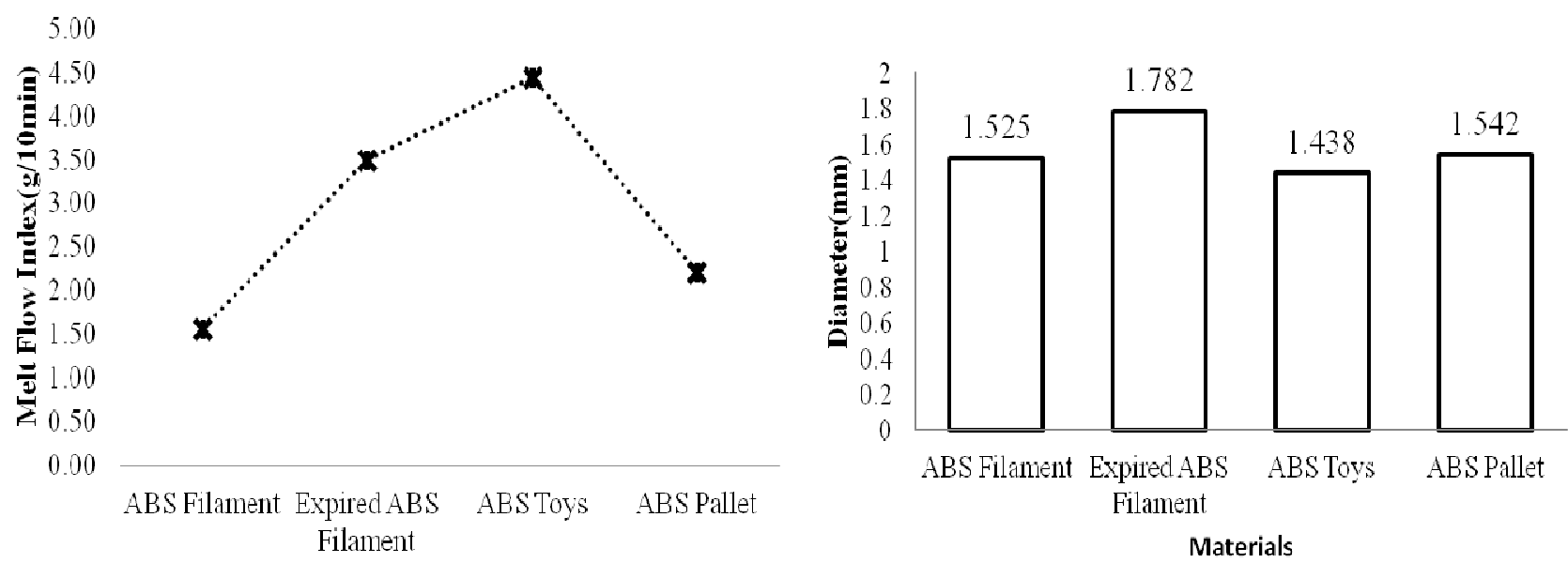

Fig 7. Melt Flow Index Results

Fig 8. Filament Diameter by the Extruder 


\section{EXPERIMENTAL RESULT}

\section{Melt Flow Index(MFI)}

From the results obtained, the highest value of MFI was ABS toys with $4.440 \mathrm{~g} / 10 \mathrm{mins}$ approximately. Then, the MFI value for ABS pallet is $2.210 \mathrm{~g} / 10 \mathrm{mins}$, ABS filament 1.567 $\mathrm{g} / 10$ mins and an expired ABS filament was $3.500 \mathrm{~g} / 10 \mathrm{mins}$. It can be concluded that the maximum MFI value came from recycle ABS toys, where the product was produce by injection moulding process. The highest MFI was need to produce a filament wire for Fused Deposition Modelling Machine. Figure 7 show the MFI result of ABS material from pallet and filament form.

\section{Filament Diameter}

The selection of recycle ABS toys was used to fabricate a filament wire of $1.75 \mathrm{~mm} \sim 1.78 \mathrm{~mm}$ in diameter approximately by the single screw extruder machine. From the results obtained, it was found that, an increament of temperature in nozzle zones lead a material in slurry material and it difficult to form the material in filement form. When the tempereture reduce on nozzle zone, the material did't melt properly and the buckling was occured during filament fabrication. It was concluded that, the constant diameter with smotthest flow to produce filament of $1.75 \mathrm{~mm} \sim 1.78$ $\mathrm{mm}$ was perpendicularly depending on the temperature setting in nozzle and barrel zones. The fabrication of filament from recycle ABS toys are shows in Figure 8 until Figure 10 by single srcew extruder machine. The best temperature setting in four zones(Figure 11) by single screw extruder was show in Table 3.

Table 3 Temperature Setting for ABS Toys by single screw extruder

\begin{tabular}{|c|c|c|c|}
\hline Feed & Barrel 1 & Barrel 2 & Nozzle \\
\hline 145 & 160 & 180 & 150 \\
\hline
\end{tabular}

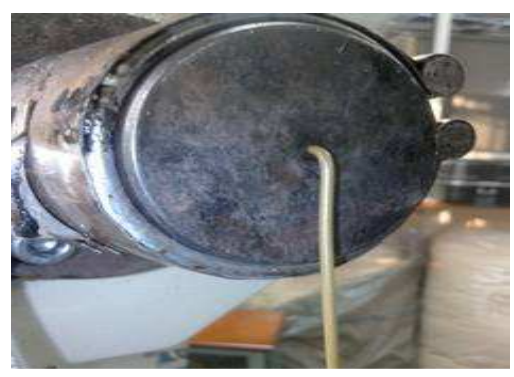

Fig 9. Filament Produce by Extruder Machine

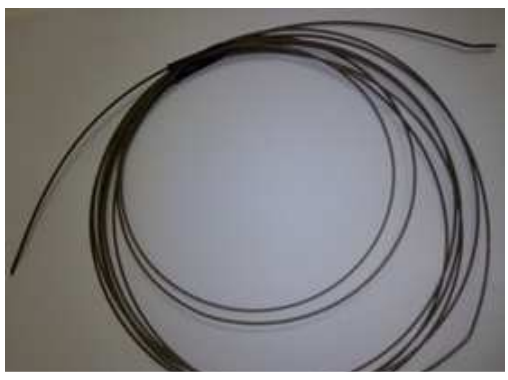

Fig 10. Filament wire from recycle ABS

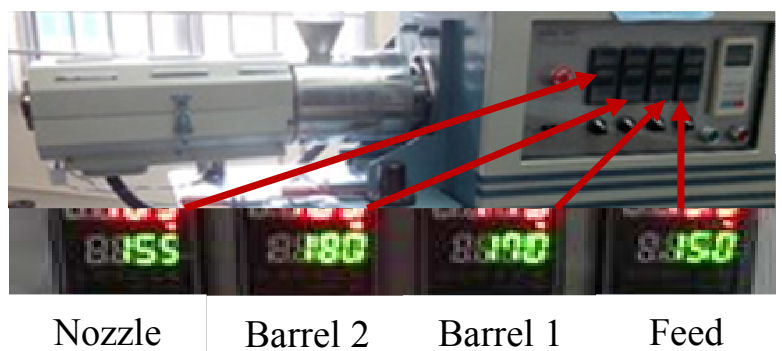

Fig 11. Four Zone Temperature in Single Screw

\section{Conclusions}

A recycle ABS material has been successfully tested on density and MFI results. Based on the results obtained in the experimental, it can be concluded that recycled ABS materials can be reused to produce a filament by using a single screw extruder machine with par condition compared with a 
ABS filament, expired ABS filament and ABS pallets material. By controlling the temperature and screw speed in the extrusion process will affects the physical properties of the filament with constant diameter filament. When the higher temperatures was used, the filament may become brittle and material flow did't smooth during filament fabrication process. The best temperature setting in the experimental was are $145^{\circ} \mathrm{C}$ at the feed zone, $160^{\circ} \mathrm{C}$ in the compression zone, $180^{\circ}$ $\mathrm{C}$ in the metering zone and $150^{\circ} \mathrm{C}$ at the nozzle zone.

\section{References}

[1] B. H. Lee, J. Abdullah, and Z. A. Khan, Optimization of Rapid Prototyping Parameters for Production of Flexible ABS Object, J. of Materials Processing Technology, 169, 2005, 54-61.

[2] M. Nidzad, S. H. Masood, I. Sbarski and A. Groth, A study of Melt Flow analysis of an ABSIron composite in Fused Deposition Modeling Process, Tsinghua Science and Technology, 14(1), 2009, 29-37.

[3] M. Nidzad, S. H. Masood, I. Sbarski, Thermo Mechanical Properties of a highly filled Polymeric Composites for Fused Deposition Modeling, J.of Materials and Design, 32, 2011, 3448-3456.

[4] J. Tyberg and J. H. Bohn, FDM Systems and local adaptive slicing, J.of Materials and Design, 20, 1999, 77-82.

[5] A. K. Sood, R. K. Ohdar and S. S. Mahapatra, Improving dimensional accuracy of Fused Deposition Modelling Processed part using grey Taguchi Method, J.of Materials and Design, 30, 2009, 4243-4252.

[6] S. H. Masood, Intelligent Rapid Prototyping with Fused Deposition Modelling, Rapid Prototyping Journal, 2(1), 1996, 24-33.

[7] A. Bellini and S. G. M. Bertoldi, Liquefier Dynamics in Fused Deposition, J. of Manufacturing Science and Engineering, 126, 2004, 237-246.

[8] C. Bellehum, L. Li, Q. Sun and P. Gu, Modeling of bond formation between Polymer Filaments in the Fused Deposition Modeling Process, J. of Manufacturing Process, 6(2), 2004, 170-178.

[9] S. H. Masood and W. Q. Song, Development of new metal/polymer materials for Rapid Tooling using Fused Deposition Modeling, J.of Materials and Design, 25, 2004, 587-594.

[10] S. H. Masood and W. Q. Song, Thermal Charecteristics of a new metal/polymer material for FDM Rapid Prototyping Process, Research articles: Assembly Automation 25/4, 2005, 309315, Emerald Group Publishing Limited.

[11]N. Sa'ude, M. Ibrahim and M. H. I. Ibrahim, Mechanical Properties of Highly Filled Iron-ABS Composites in Injection Molding for FDM wire Filament, Materials Science Forum Vols. 773774 (2014) pp 456-461.

[12]Sa'ude, N., Masood, S. H., Nikzad, M., Ibrahim, M., Ibrahim, M. H. I., Dynamic Mechanical Properties of Copper-ABS Composites for FDM Feedstock, International Journal of Engineering Research and Applications (IJERA), Vol. 3, Issue 3, Jun 2013, pp.1257-1263.

[13]N. Sa'ude, N.M.A. Isa, M. Ibrahim and M. H. I. Ibrahim, A Study on Contact Angle and Surface Tension on Copper-ABS for FDM Feedstock, Applied Mechanics and Materials Vol. 607 (2014) pp 747-751, Trans Tech Publications, Switzerland. 